\title{
Dr. SOUZA LIMA
}

Filho do C. ${ }^{\text {el }}$ Severo de Souza Lima e D. Nympha Sinfronia de Araujo Lima, nasceu, o Dr. Souza Lima aos I I de Abril de i842 em Cuyabá, Capital de Matto-Grosso.

Alli mesmo cursou uma escola de primeiras lettras, vindo depois com seus paes de volta para o Rio de Janeiro em 1849, fazendo a viagem por terra em quatro mezes.

Foram residir em Nictheroy, onde elle frequentou algum tempo um lyceu primario, e em I85I matriculou-se no antigo Collegio D. Pedro II, onde alcançou o primeiro premio nos dous primeiros annos, menção honrosa no terceiro e segundo premio no quarto.

Bacharelou-se em 1858 , tendo antes perdido ó seu pae, que falleceu em 1857 , no Pará, deixando-o em condições precarias entregue aos cuidados de uma sua tia (a mãe do Dr. Caetano d'Almeida), a cujo amparo deveu ter podido continuar os estudos; por seu lado elle já fazia pela vida ganhando um pouco de algumas licções particulares.

Em I 859 matriculou-se na Faculdade de Medicina ( $\mathrm{I}$ ), tendo sido no quarto anno alumno pensiotincções).

(1) Tendo tido approvação plena em todo o curso: (não havia dis- 
nista do Hospital de Misericordia; no quinto anno, interno de clinica cirurgica, e no sexto interno de clinica medica: (os lugares de interno eram providos por concurso, sendo que o de cirurgia não se effectuou por ser elle o unico inscripto, e o de medicina realizou-se, concorrendo com elle cinco collegas-Basilio Duque, (que foi o primeiro classificado), Pereira de Souza, Pereira Guimarães, Serafim de Abreu e Joaquim Pedro; elle foi o segundo classificado, mas os lugares eram dous).

Doutorou-se em i 864 , retirando-se logo para a fazenda de um amigo no Realengo, freguezia de Campo Grande, onde iniciou a sua clinica com tal sorte, que no anno seguinte tomou casa e casou em primeiras nupcias com D. Izabel Augusta da Silva Campos, prima-irmã delle, e que já a esse tempo (não ignorando elle) apresentava as primeiras manifestações suspeitas da horrenda enfermidade a que veiu a succumbir em i 877 .

Nesse primeiro anno de formado, 1865 , foi nomeado Delegado da Junta de hygiene publica na fre. guezia de Campo Grande, e medico da Escola de Tiro, no Realengo, onde serviu gratuitamente por offerecimento proprio, o outro cargo sendo tambem gratuito.

Em I 866 foi nomeado Tenente cirurgião do setimo batalhão da Guarda Nacional, em cujo aquartelamento teve de acompanhar, em Outubro do mesmo anno, quando tocou-lhe a vez de fornecer contingente para engrossar as fileiras do exercito em operações no Paraguay (I).

Durante o aquartelamento no quartel dos Barbonos, dando-se, o uxoricidio praticado pelo Dr. José

(I) Por este serviço foi agraciado em 187 I com o habito de Cav. da Ordem da Rosa. 
Marianno, então cirurgião mór do corpo policial, foi elle designado para substituil-o interinamente até que voltasse do Sul o legitimo substituto, que era o Dr. Guimarães Bilac.

Nesse rnesmo anno conseguiu um lugar de medico interno do Hospital de Misericordia, passando em Fevereiro do anno seguinte a Ajudante do Director do Serviço Sanitario do mesmo hospital, que era então o Dr. J. Christovão dos Santos.

Em I 868 propoz-se e foi acceito para occupar, em commissão, um lugar de Oppositor da Secção de Sciencias Accessorias (assim se chamava) na Faculdade de Medicina, oncle serviu um anno como director da Officina de Pharmacia, na rua do Areal, e dous annos como preparador das cadeiras de chimica mineral e organica: fóra já elle regia a cadeira de chimica no Externato Aquino.

Concluida a campanha do Paraguay abriu-se em I 8 i o concurso de tres lugares de oppositor da referida secção, inscrevendo-se elle e o Dr. Ramiz Galvão. Por circumstancias que não vem ao caso assignalar (um escandalo, em todo o caso) reabriu-se a inscripção que já estava encerrada, entrando os Drs. Rego Filho e Domingos Freire; tendo sido classificados em primeiro lugar elle, Souza Lima, em segundo lugar Ramiz Galvão e Domingos Freire em terceiro e os tres nomeados.

Já tendo transferido definitivamente a sua residencia no Realengo para a Côrte (rua da Misericordia) foi ainda, em i 87 r nomeado delegado da Junta Central de hygiene publica na freguezia de S. José, e depois presidente da respectiva commissão sanitaria.

Em I 873, não obstante o augmento consideravel da clinica, que lhe proporcionou uma das maiores 
epidemias de febre amarella e pelo que recebeu de presente, offerecido pela pobreza da freguezia de São José, o seu retrato a oleo de corpo inteiro, fez parte, juntamente com os Drs. Ezequiel e Borges da Costa, de uma commissão nomeada pelo Cons. João Alfredo (então ministro do Imperio) para proceder nas respectivas fontes á analyse das aguas de Caxambú e Lambary, e no anno seguinte das de Poços de Caldas.

Em I874 em virtude de jubilação concedida ao B. da Villa da Barra, foi a sua cadeira (chimica organica) posta em concurso, para o qual só se inscreveram elle e Domingos Freire; concurso tornado celebre em razão da attitude assumida pelo Dr. Ferreira de Abreu (então director interino) que na prova pratica interveio contra a lei, interrompendo-o com insistencia, até conseguir perturbal-o, afim de enfraquecer ou mesmo inutilisar o valor dessa prova, que se acreditava dever decidir esse pleito.

A parcialidade em favor do seu competidor tornou-se patente e escandalosa, visto não ser elle arguido, nem por aquelle professor, nem por outro, tratando-se do mesmo ponto, e accusando ambos, pelo mesmo ensaio a presença do acido sulfurico no acido acetico dado para exame de sua pureza e concentração! Ainda assim a differença para o primeiro lugar foi apenas de tres votos entre quinze lentes, em favor do Dr. Freire, cuja superioridade sobre elle, Souza Lima neste segundo concurso, coincidiu singularmente com a circumstancia de já ser aquelle, o Dr. Freire, então parente do ministro do Imperio, o Cons. João Alfredo, (casado com uma sua prima e afilhada. .): tambem por outra coincidencia não menos singular, não tardou muito a que o Dr. Ferreira de Abreu passasse a ser o Barão de Therezopolis. . 
Tal foi a sensação causada por aquelle resultado, que levou o Barão de Maceió a propor na Camara dos Deputados, e conseguir que fosse supprimido o concurso entre substitutos para provimento á cathedratico; vantagem de que Souza Lima veio a gosar tres annos depois, quando (irrisão da sorte) falleceu o Barão de Therezopolis, tocando-lhe por antiguidade a sua cadeira!.

Em 1876 foi nomeado, como o Dr. Borges da Costa, membro auxiliar (chimico) da Junta Central de hygiene publica. Foi esse anno tambem assignalado por uma das mais intensas epidemias de febre amarella, cujo trabalho clinico valeo-lhe outra offerta da pobreza da mesma freguezia de S. José, um tilbury, com cavallos, arreios, etc., etc. Tendo o governo creado cinco enfermarias de isolamento para os epidenicos, em varios pontos da cidade foi elle encarregado de dirigir a de Sta. Rita, situada no predio da rua de S. Bento esquina da da Prainha; e por esse serviço foi condecorado com o Officialato da Ordem da Rosa em I 877: anno de recordações successivamente jubilosas e tristes, porque, logo depois de nomeado lente cathedratico de Medicina legal, adoeceu gravemente, escapando de morrer em consequencia de um pleuriz, com vasto derrame, felizmente unilateral. Apenas ainda convalescendo, teve de ver succumbir sua mulher após doze annos e nove mezes de cruciantes padecimentos. Só, sem filhos, não puclendo supportar a viuvez por mais de um anno, em Novembro de I 878 contrahio novo enlace com a Exm. ${ }^{a}$ Snra. D. Francisca Telles do Amaral, iclolo de sua constante veneração, e da qual não existe tambem prole.

Em 1879 entrou para a Academia (então Imperial) de Medicina, onde, depois de membro titular, occupou varios cargos, inclusive o de Presidente, durante dez annos, dos quaes sete consecutivos (de i 883 a i 889 ). 
Naquelle anno fatal de r 879 em que foi decretada e posta em execução a lei do ensino livre (?), de I9 de Abril, soffreu elle um dos maiores contratempos da sua vidä publica, com a attitude offensiva e injuriosa assumida na imprensa pelos $60^{\circ}$ annistas de então, que, deante das justas e paternaes admoestações de maior severidade e rigor nos exames, que iam ser a base unica do respectivo julgamento, com a suppressão expressa das licções e sabbatinas, e dos pontos para os mesmos exames, (vagos e abrangendo toda a materia) rebellaram-se contra os seus lentes e particularmente contra elle, e conseguiram do Ministro, então Cons. Sodré Pereira, transferencia para a Faculdade da Bahia, afim de lá prestarem os exames e se doutorarem, contra o voto da congrregação, que foi dado de accordo com o disposto nos estatutos vigentes na epocha.

Dous annos depois, em 188I, teve a fortuna de poder inaugurar a parte thanatologica do curso pratico da cadeira, no Necroterio, que até ahi não era ensinado. Nesse mesmo anno, elle e o Dr. Borges da Costa foram providos nos cargos de medicos consultantes da Policia, para proceder as analyses toxicologicas e a outros ensaios de chimica legal affectos a essa repartição; mas, em I 883, com o apparecimento do primeiro decreto prohibindo accumulação de empregos remuncrados, foram dispensados daquelles cargos, voltando os alludidos exames a ser feitos no laboratorio de toxicologia da Faculdade de Medicina a cargo do lente de medicina legal, que era elle, continuando, portanto, a exercer gratuitamente para a Policia, uma funcção com a qual havia sido julgado incompatibilisado, ganhando!. Durou, porém, pouco a vigencia dessa medida, com a nomeação do Dr. Antonio Maria Teixeira para occupar, só, o lugar preenchido antes por dous, e não obstante ser este, 
então preparador da cadeira de medicina legal, como era antes o Dr. Borges da Costa, desaccumulado por isso!! . .

Em I 882 era já socio effectivo da Sociedade Auxiliadora da Industria Nacional, oncle exerceu varios cargos (desde o de membro da secção de chimica industrial e geologia applicada, secretario geral, vicepresidente, até o de presidente, na vaga deixada pela morte do Dr. Nicolau Moreira, e até 1900 em que foi substituido pelo Cons. Manoel Francisco Corrêa), tendo sido, pela parte que tomou em varias exposições nacionaes, agraciado nesse anno com a commenda da Ordem da Rosa.

Nesse mesmo annp de 1882 foi nomeado pelo Visconde de Jaguary, então Provedor da Santa Casa da Misericordia, medico director do Hopicio D. Pedro II, e logo depois medico do Recolhimento de Santa Thereza, a cargo da mesma Irmandade. Permaneceu cinco annos na direcção daquelle estabelecimento até que, em I 888, por uma questão levantada pelo Dr. Teixeira Brandão contra elle, a proposito do diagnostico de beriberi em doentes do Hospicio, na enfermaria a seu cargo, aquelle, o Dr. Brandão, obteve do Provedor, então o saudosissimo e horrado Barão de Cotegipe, a nomeação de uma commissão, que concluiu negando aquelle diagnostico formulado por elle, a favor portanto desse collega, com o qual por isso se julgou incompatibilisado, pedindo com insistencia e a custo alcançou a sua exoneração. Levada a questão ao seio da Academia de medicina, ahi Souza Lima teve a fortuna de ver o seu parecer suffragado pelos Drs. Lacerda, Francisco de Castro e Erico Coelho, não tendo o Dr. Brandão logrado uma palavra, um voto em sua defeza, e acabando por con. fessar que o relatorio da tal commissão não era um trabalho scientifico (!); o que tudo consta de um fo- 
lheto que corre impresso extrahido dos boletins da Academia (I).

Em I883, como já ficou dito foi pela primeira vez eleito presidente da Academia de Medicina, em substituição ao B. do Lavradio, unico que occupou mais tempo do que elle, esse cargo, como se sabe, de eleição annual.

Nesse anno já sendo socio honorario do Instituto pharmaceutico do Rio de Janeiro, foi acclamado presidente da Seç̧ão de physica e depois de materia medica. Em i 885 foi eleito membro correspondente do "Circulo medico argentino» e da Sociedade de medicina legal de New-York. Em i 886 foi nomeado membro da Inspectoria Geral de Hygiene presidida pelo Visconde de Ibituruna, a quem foi mandado substituir na vaga deixada pela sua exoneração (a pedido), até que foi preenchido o lugar com a inesperada romeação do Dr. Rocha Faria. Apezar de toda a competencia deste professor, e das bôas relações entre ambos, entendeu Souza Lima que era uma preterição desairosa para elle e solicitou sua exoneração, sendo substituido pelo Dr. Martins Teixeira, republicano como elle (então), o que invalidava por completo a versão de que tal era o motivo da preferencia dada ao monarchista Rocha Faria.

Em todo o caso, isso mais acendeu em seu espirito o culto por aquelle regimen, e considerou-se incompatibilisado com o cargo de presidente de uma Academia Imperial de medicina; pelo que na eleição de Julho de 1889 , sendo unanimemente reeleito para esse honroso posto, recusou, agradecendo aos seus collegas, mas protestando a continuação dos seus ser-

(I) Commissão que Souza Lima podia ter acoimado de suspeita, ao menos quanto ao seu presidente (Torres Homem) cujo laudo os outros (Benicio e P. Affonso subscreveram). 
viços e esforço em beneficio da Instituição, na qualidade de simples membro: Mal sabia elle que apenas quatro mezes depois rebentaria a sedição militar e desta a proclamação da republica brasileira. E já no anno seguinte recebia elle a reparação daquella injusta preterição, sendo chamado pelo Dr. Cesario Alvim, então ministro do Interior, para occupar o cargo de Inspector geral de hygiene, que teve de deixar alguns mezes depois, quando ministro o Dr. João Barbalho, em virtude, já agóra do principio constitucional, vedando a accumulação de cargos renumerados. Era a segunda tentativa de execução dessa lei, mallograda ainda dessa vez pela decisão, não me lembro se do Congresso ou do Poder judiciario a que recorreram os interessados, conseguindo sua reintegração muitos dos desaccumulados: Souza Lima não o fez porque nunca se apaixonou pelo exercicio de semelhante cargo, que é um verdadeiro posto de sacrificios.

$\mathrm{O}$ anno de 1890 assignalou-se para elle por mais uma reparação (le injustiça, e foi a que partio dos doutorandos desse anno, elegendo-o seu paranympho na collação de gráu. Foi nomeado para substituir ${ }^{\star}$ o Dr. Freire, então ausente na Europa, no lugar de membro do Conselho Superior de Instrucção publica (hoje extincto); nesse mesmo anno recebendo do Governo francez o gráu de Official de Instrucção publica.

Em 1892 installando-se no Rio de Janeiro a Faculdade Livre de Sciencias Juridicas e Sociaes, foi convidado para reger a cadeira de medicina legal, depois a de hygiene, e finalmente a de medicina publica, em que numa das ultimas reformas fundiram-se aquellas duas disciplinas; tendo sido no mesmo anno escolhido Vice-Presidente honorario do Congresso de educação, a reunir-se em Chicago em 1898. 
$\mathrm{Na}$ reorganisação completa que soffreu a municipalidade com o advento da Republica, sendo Prefeito o Coronel H. Valladares foi creado o cárgo de Director de hygiene e assistencia publica, que foi elle o primeiro a occupar effectivamente e acceitou a instancias do mesmo Prefeito, que para isso foi pessioalmente á casa delle: isso foi em Julho de 1893, no mesmo anno, em cujo mez de Setembro explodiu a revolta naval chefiada pelo contra-almirante Custodio de Mello e que prolongou-se até i3 de Março do anno seguinte; constituindo um periodo de vida administrativa de mero expediente, nullificando por completo qualquer tentativa de melhoramento sanitario da cidade, toda empenhada na sua defeza bellica. Nada, portanto, poude fazer a que ligasse o seu nome, não obstante ter conseguido adquirir por compra na Europa, todo o material para a creação de um laboratorio de bromatologia, que era uma das suas preoccupações; esse material achando-se, segundo me informaram, ainda encaixotado desde essa epocha (!) guardado numa dependencia do Asylo de Mendicidade, a espera de aproveitamento..... Por falta de casa naquella occasião não realisou a sua installação; como tambem não chegou a obter terreno para construir uma enfermaria veterinaria, cuja planta, entretanto, elle já havia incumbido ao engenheiro da repartição sanitaria, para tratamento e observação das vaccas de leite, encontradas nos estabulos, doentes ou suspeitas de estarem pelos Commissarios de hygiene; uma das medidas que elle reputa capitaes na prophylaxia da tuberculose. Sem meios de desempenhar-se conscienciosamente da sua tarefa n'aquelle cargo, quando em Novembro de 1894 se annunciou o apparecimento do cholera no Valle do Parahyba, instou pela sua exoneração, deixando a outros mais felizes a responsabilidade da defeza sanitaria da cidade. Ainda em 
I 893 foi eleito socio honorario da Sociedade de hygiene do Brazil e socio correspondente da Associaçĩo medico-pharmaceutico de Pernambuco. Em I 894 effectuou-se a exposição internacional de trabalhos juridicos, á qual concorreu como lente de uma Faculdade de Direito, sendo premiado com o diploma de $2 .^{a}$ classe.

Em $\mathrm{s} 897$ foi eleito membro correspondente da Academia de Medicina de Lima (Perú) e do Instituto polytechnico da Bahia: em I 898 realisaram-se pela primeira vez no Rio de Janeiro, exames de madureza, sob a direcçăo de um Jury do qual foi elle nomeado membro e como lente rnais antigo, presidente do mesmo Jury. ( $\mathrm{I}$ )

Em I 899 foi commissionado pelo Governo de Minas para analysar as aguas medicinaes de Cambuquira, o que fez em collaboração com o Bacharel Cesar Diogo que convidou para seu auxiliar. Nesse mesmo anno reccbeu convite insistente por parte da Associaçåo do $4 .^{\circ}$ centenario do descobrimento do Brazil, para collaborar no grande livro destinado a perpetuar essa commemoração, encarregando-se de escrever a historia das sciencias medicas e pharmaceuticas no Brazil, desde 1808 até fim de I 899 , tarefa penosissima de que se desobrigou da melhor fórma que poude, attendendo ao prazo e volume curtos que lhe foram impostos e a mesquinha gratificação promettida (2:000\$000) que ainda não recebeu, segundo me consta.

Em I 900 foi escolhido orador do $4 .^{\circ}$ Congresso de Medicina e Cirurgia do Brazil, que se reunio em Julho do mesmo anno, e eleito presidente da Com- 
missão executiva do $5 .^{\circ}$ Congresso a realizar-se ainda no Rio de Janeiro, em Junho de 1903.

Effectuou-se tambem em igoo uma Exposição artistica-industrial no Lyceu de Artes e Officios, de cujo jury foi elle nomeado Presidente; acabando por ser eleito socio titular da Sociedade Propagadora de Bellas Artes, que promoveu a referida Exposição.Constituiu-se no mesmo anno a Liga brazileira contra a tuberculose, de cujo conselho consultivo foi nomeado membro e faz parte ainda. Nesse anno, cansado de esperar a reparação dos direitos dos professores que entraram no regimen das jubilações por tempo determinado e a cessação da exigencia illegal, de inspecção de saude e declaração de invalidez, illegal porque está tendo effeito retroactivo, resolveu pedir e obteve do Congresso licença por um anno, só com ordenado, que, esse mesmo lhe foi totalmente supprimido em mais 6 mezes que solicitou, esgotado aquelle anno que passou na Europa. Voltando em Junho de 1902 leccionou até o fim desse anno, pedindo então a sua jubilação, porque infelizmente achava-se, como está, bastante adoentado e incapaz de continuar o exercicio do magisterio, sendo-lhe concedida a jubilação, segundo a lei, com todos os vencimentos, por contar mais de 30 annos effectivos de serviço docente, no dia 8 de Dezembro de 1902. Nesse anno, ainda foi eleito socio correspondente da Sociedade de Psychologia de São Paulo; em 1903 a commissão directora do $3 .^{\circ}$ congresso latino-americano, a reunir-se no Rio de Janeiro em 1905, nomeou-o presidente da secção de medicina publica, na vaga deixada pela morte do sabio e insubstituivel Manoel Victorino.

Além de muitos outros cargos que occupou, uns de ordem scientifica e outros extranhos, mas, em todo o caso de elevada importancia e que deixo de 
mencionar, Souza Lima escreveu e publicou os seguintes trabalhos: a) These de doutoramento sobre «Chyluria, sua natureza e tratamento; razão de sua frequencia nos paizes quentes; b) These de concurso para oppositor da secção de sciencias accessorias sobre «Imcompatibilidades sob o ponto de vista Chimico pharmacologico»; c) These de concurso para a cadeira de chimica organica sobre «Série cyanica»; d) Relatorios diversos sobre analyses de aguas mineraes quer só, quer em collaboração; e) idem sobre o serviço da enfermaria de febre amarella, de que foi director em I876; f) Estudo sobre «a Cremação dos Cadaveres, contendo, a memoria que lhe deu entrada na Academia de Medicina; g) Numerosos artigos sobre varios assumptos da Cadeira em differentes jornaes e Revistas (do Rio, de S. Paulo e da Bahia, de medicina como de jurisprudencia) e particularmente na Revista dos Cursos da Faculdade de Medicina, na qual, durante todo o tempo de sua existencia, não ha um só numero que não traga artigo seu; sendo mesmo o unico professor que se póde gabar dissso (si é motivo para vangloria).

Publicou em I 890 o seu primeiro tratado de toxicologia, cuja impressão foi paga pelo Governo, que ainda o premiou com a quantia de dous contos de réis, sob parecer muito honroso da congregação. Em I 893 publicou o manual da Chimica legal, que em I 897 fundio em segunda edição com a parte clinica de toxicologia, eliminando a parte da pesquiza toxicologica, que uma reforma do ensino medico supprimio da cadeira de medicina legal para incorporar á de chimica analytica, creada por essa reforma.

Em I895 publicou o seu primeiro volume de seu Tratado de Medicina legal; e como desde essa epocha se lançou no Parlamento a idéa da reforma 
do Codigo penal, que chegou mesmo a ser votado na Camara, encalhando no Senado, tem esperado essa reforma para escrever e publicar o segundo volume, todo consagrado, segundo estou informado, a questões que affectam o referido Codigo: Cansado de esperar, consta-me, reeditará o mais breve possivel o primeiro volume correto e augmentado para esse fim.

Por mais que me esforçasse, não me foi possivel colher outros dados relativos á vida de quem, qual Souza Lima, é um benemerito da patria.

Bem sei que certas revelações aqui feitas vão melindrar o sabio professor; mas elle que me perdoe. Agora que jubilado terá talvez de dormir sobre os seus louros é justo que ao menos alguem, mesmo incompetente como eu, tenha a coragem de publicamente confessar que o Dr. Suuza Lima foi o verdadeiro interprete da disciplina que por mais de 30 an nos leccionou, na Faculdade de Medicina do Rio; foi quem, sem ter ainda hoje quem o imite, soube incutir aos alumnos a necessidade do estudo da medicina judiciaria, tão descuidada até então: foi, em summa, como é ainda para mim, o oraculo cujos ensinamentos tanto tranquilisam os que têm de se pronunciar sobre os differentes problemas cuja solução importam a liberdade, honra e vida dos seus semelhantes.

Sirvam estas palavras de consolo e conforto as agruras e quiçá, tristezas, que teve durante o ternpo do inagisterio.

S. Paulo, 6 de Abril I903.

Dr. Amancio de Carvalho. 